\title{
Do Interbank Interest Rates Matter for Stock Prices at Nepal Stock Exchange?
}

\author{
Rajesh Gurung \\ Lecturer, Nepal Commerce Campus, T.U.
}

\begin{abstract}
This study examines an auto-regressive distributed lag (ADRL) modeling approach to develop the relationship between the stock price and interest rate in the context of Nepal, using the monthly data for the period from July 1996 to January 2019. NEPSE Index in Nepal Stock Exchange Limited is used for the stock prices and interbank interest rate released in Quarterly Economic Bulletin of Nepal Rastra Bank is used for the interest rate. The bound test for co-integration and estimated negative coefficient of long-run regression results justified by the Error Correction Mechanisms (ECM) establishes a valid negative long-run association between the INTEREST and PRICE. This suggests important considerations for policies towards an interest rate stabilization for the stock price stability and further development of the stock market in Nepal.
\end{abstract}

Keywords: Interest, Price, ADRL

\section{Introduction}

The finance-economic theory argues for the developed stock market in ensuring long-term capital to promote the real economic activity of a country. For instance; Morck, Shleifer, and Vishny (1990) claim that the debates over stock market efficiency would not be important if the stock market did not affect real economic activity then the market inefficiencies would merely redistribute wealth between smark investors and noise traders. However, the stock market if influences real economic activity, the investors' sentiment that affects stock prices could also indirectly affect the real activity. This entails measuring the stock market efficiency as imperative from the viewpoint of investors, policymakers, and other market participants. Moreover, a well-developed stock market is perceived as a yardstick of the economic health and prospect of a country.

Interest rate is an important macro-economic component and as a cost of credit to the borrowing firms, any change in the rate can cause the profit situation of the firms thereby fluctuating the prices of stocks of the companies. As the news regarding the change in interest rate is indicative of stock price variation; this is the reason how the policy consideration becomes an imperative issue in stabilizing the interest rate in the financial system. Considerable numbers of theoretical and empirical evidence have documented the relationship between interest rates and stock prices. Fama (1981), for example, argues that the expected inflation rate as a proxy of short-term interest rate is negatively correlated with the anticipated real activity which in turn is positively related to returns on the stock market. The studies (Zhou, 1996;Uddin\& Alam, 2009; Ali, 2014; Amarasinghe, 2015 among others) have examined the relationship between the interest rate and stock prices and have concluded the negative relationship between them. However, the most recent study carried out by Eldomiaty et al. (2020), using quarterly data on non-financial firms listed in DJIA 30 and NASDAQ100 for the period 1999-2016, in a Johansen co-integration analysis have shown the stock prices are positively associated with the real interest rates, and negatively with that of the inflation rates. 
This provides the evidence of research results varying from country to country as well as the nature of data used and other methodological considerations.

\section{Methodology and Analysis}

This study employs an auto-regressive distributed lag (ADRL) modeling approach to develop the relationship between the stock price and interest rate in the context of Nepal, using the 283 monthly observations from the period from July 1996 to January 2019. NEPSE Index in Nepal Stock Exchange Limited, after the transformation in natural logarithmic form, is used for the stock prices, 'PRICE' hereafter, and interbank interest rate released in Quarterly Economic Bulletin of Nepal Rastra Bank is used as a proxy for the interest rate, 'INTEREST' hereafter. The uni-variate properties of each of these time series have been observed by plotting trends and carrying out the stationary test. The bound test of co-integration has been applied to confirm the long-run association amongst time series. The equation then re-parameterized into short-run dynamics and error correction mechanisms to validate their long-run relationship. The model diagnostic and stability is performed with serial correlation LM test and CUSUM test, respectively. The mean values and their associated standard deviations in descriptive statistics confirm the INTEREST [i.e., $3.26 \pm 2,67 \%$ ] is more fluctuating [Figure 1] as in comparison to the PRICE [i.e., $599.19 \pm 433.83$ points].

\section{Time Series Trend}

Figure 1 presents the trend of the PRICE and INTEREST, and it can be noted that the time series trend tends to move in the opposite direction. For example, the interbank interest rates from April 1998 (4.7\%) to March 1999 (0.73\%) were trended towards downward whereas index values (price) were tended towards upward (158.73 versus 180.89). Similarly, for the twelve months from August to July 2011/12, NEPSE Index trending downward with the interbank interest rate aloft. This reverse relationship between the stock price and interest rate is further justified by their negative correlation coefficients (i.e., - 0.31).

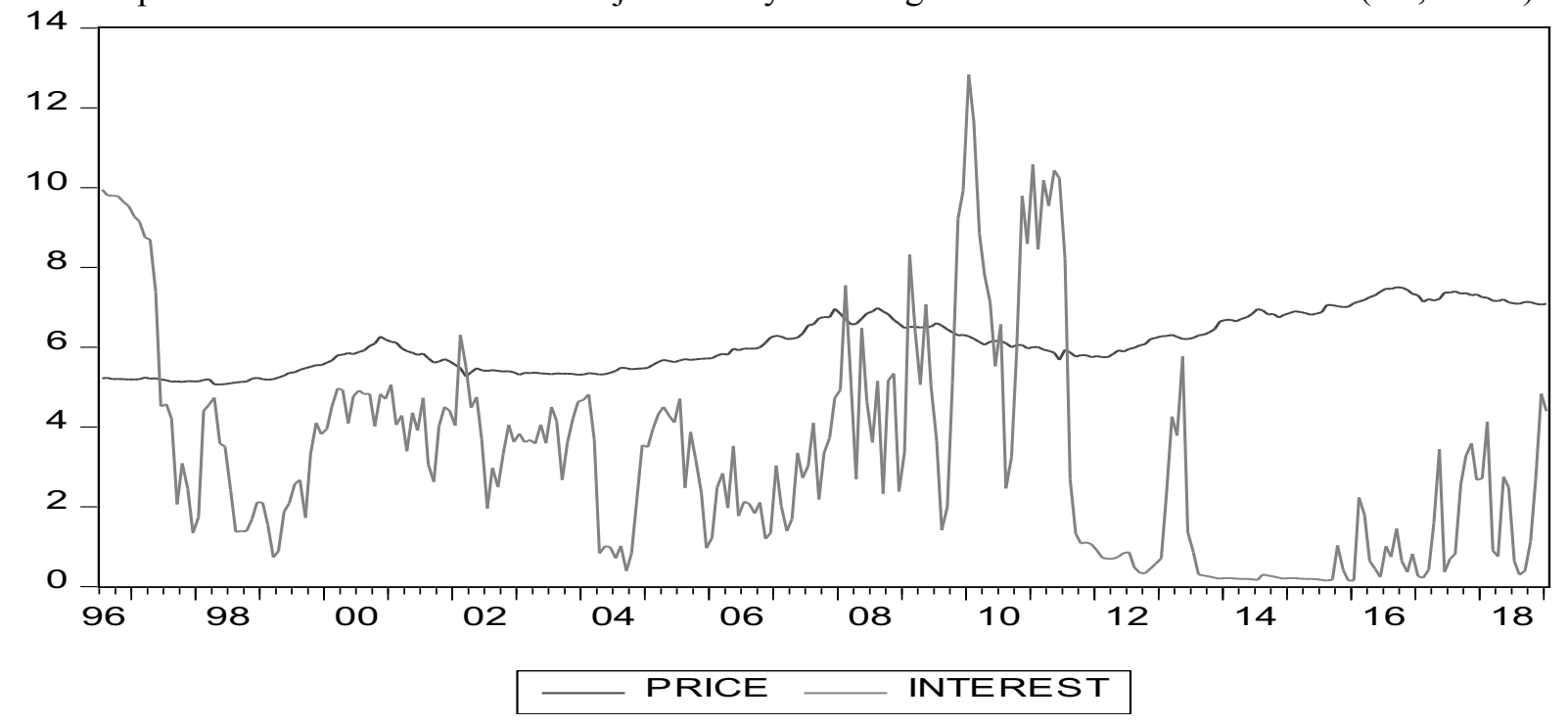

Figure 1: Time Series Trend

\section{Testing for Unit Root}

The short-run dynamics and long-run causality between these sets of variables with a different order of integration have been examined with the cointegration procedure and auto-regressive distributed lag model prescribed by Pesaran et al. (2001). After the observation of co-movements of times series over periods, a unit root test has been carried out in this section to examine the data stationary and to identify the order of integration, I(d). Equation [1a] and [1b] represents the Augmented Dickey-Fuller (ADF) tests 
for the purpose. Concerning the PRICE, the null hypothesis in Equation [1a] states that the PRICE has got unit root [i.e., $\mathrm{H}_{0}: \beta_{2}=0$ ], and regarding INTEREST, the null hypothesis in Equation [1b]] represents the INTEREST has got unit root [i.e., $\mathrm{H}_{0}: \theta_{2}=0$ ]. The null hypothesis of the time series that has got unit root would be rejected in the favor of alternative hypotheses when their respective coefficients become significantly negative [i.e., $\beta_{2}<0$ and $\theta_{2}<0$ ].

$\Delta$ PRICE $_{\mathrm{t}}=\beta_{1}+\beta 2$ PRICE $_{\mathrm{t}-1}+\mathrm{i}=1 \mathrm{~m} \beta \mathrm{i} \Delta$ PRICEt $-\mathrm{i}+e_{\mathrm{t}}$

$\Delta$ INTEREST $=\theta_{1}+\theta_{2}$ INTEREST $_{\mathrm{t}-1}+\mathrm{i}=1 \mathrm{n} \theta \mathrm{i} \Delta$ INTERESTt $\mathrm{i}+e_{\mathrm{t}} \quad[1 \mathrm{~b}]$

Whereas $\Delta$ is the difference operator; $\beta$, and $\theta$ represent the parameters of stock price and interest rate, respectively. The $e_{\mathrm{t}}$ and $e_{\mathrm{t}}$ are white noise error terms, and $\mathrm{m}$ and $\mathrm{n}$ are the maximum lengths of the series of respective time series. To avoid the specification error, the maximum number of lags has been taken 12 for each of the time series as suggested by Gujarati (2015) and Wooldridge (2009) for monthly data sets. The results of unit root tests and their respective order to integration have been reported in Table 1.

Table 1

Results for Unit Root Test

\begin{tabular}{|c|c|c|c|c|c|c|c|c|c|}
\hline \multicolumn{10}{|c|}{ Jull Hypothesis: Time series has got unit root } \\
\hline \multirow{3}{*}{ Variable } & \multicolumn{4}{|c|}{ Level } & \multicolumn{4}{|c|}{ First Difference } & \multirow{3}{*}{$\begin{array}{c}\text { Order of } \\
\text { Integration } \\
\text { I(d) }\end{array}$} \\
\hline & \multicolumn{2}{|c|}{ Intercept } & \multirow{2}{*}{$\begin{array}{c}\text { Intercept } \\
\text { t-stat }\end{array}$} & \multirow{2}{*}{$\begin{array}{r}\text { Trend } \\
\text { p-val }\end{array}$} & \multicolumn{2}{|c|}{ Intercept } & \multicolumn{2}{|c|}{ Intercept \& Trend } & \\
\hline & t-stat & p-val & & & t-stat & p-val & t-stat & $\mathrm{p}$-val & \\
\hline PRICE & -0.851 & 0.802 & -1.972 & 0.613 & $-13.391 *$ & 0.000 & $-13.367 *$ & 0.000 & $\mathrm{I}(1)$ \\
\hline INTEREST & $-4.454 *$ & 0.000 & $-4.534 *$ & 0.002 & $-17.354 *$ & 0.000 & $-17.348^{*}$ & 0.000 & $\mathrm{I}(0)$ \\
\hline
\end{tabular}

The unit root results reported in Table 1 indicated that the null hypothesis of the PRICE has got unit root cannot be rejected, both the cases with intercept and intercept \& trend, at level data; however the null hypothesis has been rejected at the first difference while running the equation with intercept and then intercept \& trend. This shows the data series of stock price exhibits the integrated of order 1, I(1). For the interest rate, the null hypothesis of the INTEREST has got unit root has been rejected at level, which evidenced the INTEREST bears an integrated of order $0, \mathrm{I}(0)$.

\section{Testing for Co-Integration}

The econometric theory argues that the two or more non-stationary (unit root) time series when integrated are unable to deviate from stable equilibrium in the long-run, and they are said to be co-integrated. This suggests the test of co-integration is an important step to establish whether the model empirically exhibits a valid long-run relationship and can be re-parameterized into an error correction mechanism. The results of the unit root tests have provided the time series with integrated of order 1 and 0; the Auto-Regressive Distributed Lag (ARDL) bound test technique, suggested by Pesaran \& Shin (1999) and Pesaran et al. (2001), can be employed to examine the co-integration between the PRICE and INTEREST [Equation 2].

$\triangle P R I C E_{t}=\alpha_{0}+i=1 P \alpha 1 i \Delta$ PRICEt-i $\alpha$ liy/Nt-i $+i=0 q \alpha 2 i \Delta$ INTERESTt $-i+\delta_{1} P R I C E t_{-1}+\delta_{2}$ INTERESTt $_{-1}+$ $e_{t} \ldots \ldots \ldots \ldots \ldots . .[2]$

Whereas $\delta_{1}$ and $\delta_{2}$ correspond to the coefficients of long-run relationships. The null hypothesis of no existence of long-run relationship (i.e., $\mathrm{H}_{0}: \delta_{1}=\delta_{2}=0$ ) between the PRICE and INTEREST is tested against the alternative hypothesis (i.e., there is a long-run relationship between PRICE and INTEREST, $\mathrm{H}_{1}: \delta_{1} \neq 0 ; \delta_{2}=0$ ). The $\alpha_{1 \mathrm{i}}$ and $\alpha_{2 \mathrm{i}}$ in the given equation are the corresponding coefficients of short-run dynamics for the PRICE and INTEREST. The F-statistic values after running the Equation [2] provides the decision regarding the long-run association between these two-time series. This F-statistic value for the long-run relationship is reported in 
Table 2.

Table 2

Bound Test for Co-Integration

\begin{tabular}{cccccccc}
\hline \multicolumn{1}{c}{ Null Hypothesis, H0: There is no level relationship } & \multicolumn{2}{c}{ Critical Value } & \multicolumn{2}{c}{10 percent } \\
$\begin{array}{c}\text { D. } \\
\text { Variable }\end{array}$ & $\begin{array}{c}\text { F- } \\
\text { Statistics }\end{array}$ & \multicolumn{2}{c}{ Lower } & Upercent & \multicolumn{2}{c}{5 percent } & \multicolumn{2}{c}{ Uper } & Lower & Upper & Lower Bound & Upper Bound \\
& & Bound I(0) & Bound I(1) & Bound I(0) & Bound I(1) & I(0) & $\mathrm{I}(1)$ \\
\hline PRICE & $\begin{array}{l}5.802^{* *} \\
(\mathrm{k}=1)\end{array}$ & 4.068 & 5.250 & 3.62 & 4.16 & 2.496 & 3.346 \\
\hline
\end{tabular}

The automatic lag selection criteria of ARDL techniques suggest an optimal number of lags of 11 for PRICE and 1 for INTEREST. Thus, the F-statistic of 5.802 for the ARDL $(11,1)$ model reported in Table 2 is higher than the upper bound I(1) critical value of 4.16 for a 5 percent level of significance and rejects the null hypothesis in the favor of the alternative hypothesis. This implies that, for a 5 percent level of significance, there exists a long-run relationship between the PRICE and INTEREST. The estimated long-run coefficients for ARDL $(11,1)$ with the PRICE as a dependent and INTEREST as an independent variable is reported as:

$$
\begin{array}{lll}
\text { PRICE } \quad=\quad \begin{array}{l}
7.757 \\
(0.000)
\end{array} & 0.424 * * * I N T E R E S T \\
(0.062)
\end{array}
$$

While the figures in the parentheses include the probability values, the coefficient of interest rate is negative 0.424 and it is significant at the 6.2 percent level. This suggests the interest rate has contributed negatively to the stock prices of the country in the long-run. In fact, for a 1 percentage point increase in the INTEREST causes to decline in PRICE almost by 42 percentage points, and vice-versa.

\section{Short-Run Dynamics and Error Correction Mechanism (ECM)}

Pesaran et al. (2001) argue that the long-run relationship justified by the ARDL bound test in Equation [2] requires re-parameterization into short-run dynamics and error correction mechanisms (ECM) to validate long-run associations among variables. More specifically, the lag long-term variables in the form of unrestricted ECM of Equation [2] are replaced by lag error correction term, $\left(\mathrm{ECT}_{\mathrm{t}-1}\right)$ allowing to estimate restricted vector auto-regressive models. Hence, it allows Equation [2] to re-specify into Equation [3] as follows. ${ }^{1}$

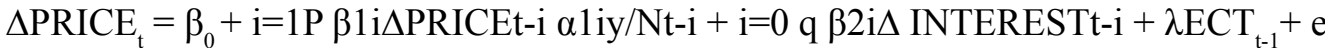

Whereas $\lambda$ in Equation [3] is a parameter that stands for speed for an adjustment, particularly it measures the extent to which any disequilibrium in the PRICE-INTEREST relationship in the previous period is being adjusted in the current period towards equilibrium. Theoretically, the coefficient of error correction term $(\lambda)$ is expected to lie between -1 and 0 that is, $-1<\lambda<0$ ) so that it allows the deviation converge towards equilibrium, whereas a positive coefficient adds towards a divergence between a set of time series. 
Table 3

ARDL Error Correction Regression, ARDL $(11,1)$

\begin{tabular}{lcccc}
\hline $\begin{array}{l}\text { Dependent Variable: D(PRICE) } \\
\text { Variable }\end{array}$ & Coefficient & Standard Error & t-Statistics & p-values \\
\hline D(PRICE(-1)) & 0.150 & 0.062 & 2.415 & 0.017 \\
D(PRICE(-2)) & 0.087 & 0.062 & 1.389 & 0.166 \\
D(PRICE(-3)) & -0.028 & 0.063 & -0.448 & 0.655 \\
D(PRICE(-4)) & -0.167 & 0.062 & -2.677 & 0.008 \\
D(PRICE(-5)) & 0.025 & 0.062 & 0.394 & 0.694 \\
D(PRICE(-6)) & 0.176 & 0.062 & 2.825 & 0.005 \\
D(PRICE(-7)) & -0.070 & 0.062 & -1.120 & 0.264 \\
D(PRICE(-8)) & -0.014 & 0.063 & -0.221 & 0.825 \\
D(PRICE(-9)) & 0.131 & 0.063 & 2.087 & 0.038 \\
D(PRICE(-10)) & 0.106 & 0.062 & 1.714 & 0.088 \\
D(INTEREST) & 0.001 & 0.003 & 0.447 & 0.655 \\
ECT(-1)* & -0.013 & 0.004 & -3.473 & 0.001 \\
\hline
\end{tabular}

Table 3 reports the selected ARDL Error Correction Regression (ARDL $(11,1)$ ) and the coefficient of error correction term is negative 0.013 and highly significant at 1 percent level. This implies that a deviation from the long-run equilibrium following a short-run shock is corrected by about 1.3 percent after each period and confirms the existence of a stable long-run relationship between the PRICE and the INTEREST. This suggests that there exists a long-run relationship between the interest rate and stock prices. This negative association between the interest rate and stock prices is similar to the findings of earlier studies in the context of Nepal (Shrestha \& Subedi, 2014; Gaire, 2017 among others). However, only the 12 percentage points variation is the PRICE is explained by the variation in the INTEREST [adjusted $\mathrm{R}^{2}=0.12$ ]. It further suggests that the interest rate is not only a factor that hurts the stock prices of Nepal. Moreover, theorists and researchers have a common understanding of the roles of quantitative and qualitative factors to influence the stock prices of a particular country, however, they have not yet agreed on specific factor/s. The earlier studies too, for instance; Dongol (2008), Joshi (2009), Pradha (2017), Bhattarai (2018), Khatri (2019), Shrestha \& Pokharel (2019) among others have documented the impact of various factors such as political factors. policy issues, macro-economic forces, and company-specific fundamentals on the stock prices of Nepal.

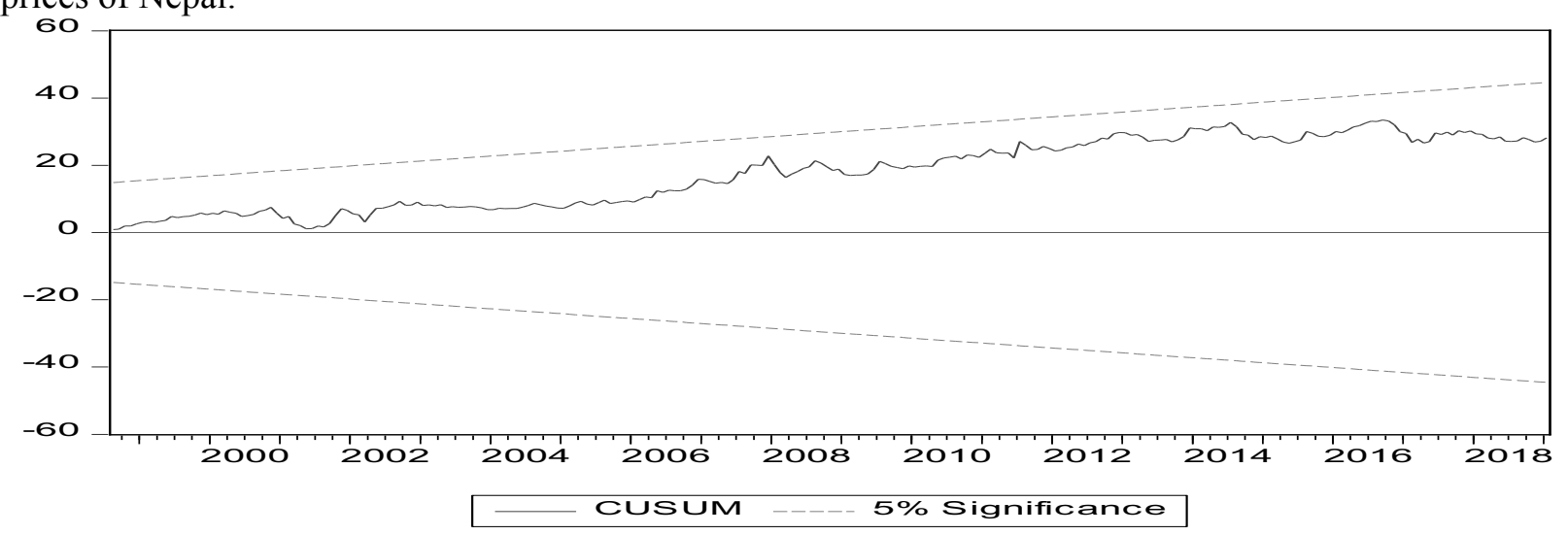

Figure 2: Plots of Cumulative Sum (CUSUM)

Since the Breusch-Godfrey Serial Correlation LM Test provides chi-square p-values [i.e., $\left.\chi^{2}(12)=9.810(0.633)\right]$ higher than 0.05 , this indicates the model with no evidence of serial 
correlation. The graphical presentation [Figure 2] presents the CUSUM Squares test for the stability of the long-run coefficients. The line that represents the values of CUSUM Squares which falls within the two critical bound (dotted lines) at the 5 percent significance level evidence the parameters in the model are stable over the period.

\section{Conclusion}

This study examined an autoregressive distributed lag (ARDL) modeling approach to develop the relationship between the INTEREST andPRICES, using the time series of 283 monthly observations from July 1996 to January 2019. The bound test of co-integration confirms the long-run association and it is further justified by the significant speed of adjustment in the short-run shock towards the long-run equilibrium. This concludes the interest rate has caused the stock prices in the long-run in Nepal. This finding provides important considerations for policies towards an interest rate stabilization for the stock price stability and further development of the stock market in Nepal. Furthermore, the interest rate is not only a factor that hurts the stock prices but there can be many other quantitative and qualitative factors that causing the stock prices to suffer. Therefore, similar research can be further carried out with more inclusive variables, time horizon, and methodology.

\section{References}

Ali, H. (2014). Impact of Interest Rate on Stock Market: Evidence from Pakistani Market. Journal of Business and Management, 64-69.

Amarasinghe, A. (2015). Dynamic Relationship between Interest Rate and Stock Price: Empirical Evidence from Colombo Stock Exchange. International Journal of Business and Social Science, 92-97.

Bhattarai, B. P. (2018). The Firm-Specific and Macro-Economic Variables Effects on Share Prices of Nepalese Commercial Banks and Insurance Companies. Review of Integrative Business \& Economics Research, 1-11.

Dongol, J. (2008). Unanticipated Political Events and Stock Returns: An Event Study. Economic Review, 86-110.

Fama, E. (1981). Stock Returns, Real Activity, Inflation and Money. . American Economic Review, 545564.

Gujarati, D. (2015). Econometrics by Example. UK: Palgrave.

Khatri, M. (2019). Macro-Economic Influence on the Nepalese Stock Market. NRB Economic Review, 4562.

Morck, R., Shleifer, A., \& Vishny, R. W. (1990). The Stock Market and Investment: Is the Market a Sideshow? Brookings Papers on Economic Activity, 157-215.

Pesaran, M. H., \& Shin, Y. (1999). An Autoregressive Distributed Lag Modelling Approach Analysis: Econometrics and Economic Theory in the 20th Century. Cambridge: Cambridge University Press.

Pesaran, M. H., Shin, Y., \& Smith, R. J. (2001). Bounds Testing Approaches to the Analysis of Level Relationships. Journal of Applied Econometrics, 289-326.

Pradhan, R. S., \& Sapkota, A. K. (2016). Impact of Firm-Specific and Macro-Economic Variables to Determine of Share Prices of Nepalese Commercial Banks. Journal of Management and Development Economics, 1-16.

Shrestha, P. K., \& Pokharel, S. (2019). Factors Affecting Stock Index in Nepal. SEBON Journal, 33.52.

Uddin, M. G., \& Alam, M. M. (2007). The Impacts of Interest Rate on Stock Market: Empirical Evidence from Dhaka Stock Exchange. South Asian Journal of Management and Sciences, 123-132.

Wooldridge, J. M. (2013). Introductory Econometrics: A Modern Approach. USA: South_Western Cengage Learning.

Zhou, C. (1996). Stock Market Fluctuations and the Term Structure: Finance and Economics Discussion Series. U.S.: Board of Governors of the Federal Reserve System. 